\title{
A CAUCHY-BUNYAKOVSKY-SCHWARZ TYPE INEQUALITY RELATED TO THE MÖBIUS ADDITION
}

\author{
KEIICHI WATANABE
}

Abstract. We show a Cauchy-Bunyakovsky-Schwarz type inequality related to the Möbius addition in complex inner product spaces. The corresponding inequality in real inner product spaces can be derived easily as well.

Mathematics subject classification (2010): Primary 46C05, Secondary, 26D20, 46T99.

Keywords and phrases: Schwarz inequality, Möbius addition, Möbius gyrogroup, Möbius gyrovector space.

\section{REFERENCES}

[1] John B. Conway, A Course in Functional Analysis, 2nd edition Springer-Verlag, Graduate Texts in Mathematics 96, New York, 1990.

[2] Abraham A. Ungar, Analytic Hyperbolic Geometry and Albert Einstein's Special Theory of Relativity, World Scientific Publishing Co. Pte. Ltd., Singapore, 2008.

[3] A. A. UNGAR, Extension of the unit disk gyrogroup into the unit ball of any real inner product space, J. Math. Anal. Appl. 202, 3 (1996), 1040-1057.

[4] A. A. UngaR, Group-like structure underlying the unit ball in real inner product spaces, Results Math. 18, 3-4 (1990), 355-364.

[5] A. A. UNGAR, Thomas rotation and the parametrization of the Lorentz transformation group, Found. Phys. Lett. 1, 1 (1988), 57-89.

[6] K. Watanabe, Orthogonal Gyroexpansion in Möbius Gyrovector Spaces, J. Funct. Spaces 2017, (2017), Article ID 1518254, doi:10.1155/2017/1518254, 13 pages. 